\title{
TEORIA E PRÁTICA: CORRELAÇÃO NECESSÁRIA NO PROCESSO DE APRENDIZAGEM DA MATEMÁTICA
}

\section{THEORY AND PRACTICE: CORRELATION NECESSARY IN THE MATHEMATICS LEARNING PROCESS}

\author{
Carina Geovanna Nepomuceno Bezerra ${ }^{1}$; Johnny Wostinson Alves Araujo²; Antonio \\ Evangelista Ferreira Filho ${ }^{3}$; Francisca da Rocha Barros Batista ${ }^{4}$.
}

\section{INTRODUÇÃO}

Quando se realiza uma atividade no cotidiano, dificilmente a situação dos acontecimentos é relacionada a alguma disciplina, inclusive à matemática, independente da tarefa que está sendo executada. Esquece-se das aulas ministradas pelos mestres e das fórmulas que foram traçadas na lousa (CUNHA, 2017).

Cunha (2017) enfatiza que a matemática está presente em todos os segmentos da vida e em todas as tarefas executadas do nosso dia a dia, seja na compra de um simples pão como na aplicação de um grande investimento financeiro. Assim, ao acordar, o despertador expressa as horas utilizando o princípio da contagem do tempo, quando fazemos uma refeição utilizamos o conceito da proporção, e assim por diante.

Porém, a matemática é aceita com insatisfação pela comunidade escolar, pois exige dos estudantes um grau de memorização e uma ampla linha de raciocínio, dificuldades que os fazem distanciar-se de sua prática no cotidiano (CUNHA, 2017). Talvez esse distanciamento ocorra porque a escola nem sempre faz relação entre a teoria e a prática do dia a dia dos alunos.

Fundamentado nas ideias postas, esta experiência foi desenvolvida com o intuito de identificar, por meio de uma pesquisa de campo, a importância da prática no processo de aprendizagem da matemática. Para tanto, o objetivo é de investigar a relevância da matemática e suas aplicações, especificamente no cotidiano de horticultores, identificando o grau de escolaridade e instrução dessas pessoas, bem como o resultado de suas atividades de plantio e colheita.

\section{RELATO DE EXPERIÊNCIA}

De início, selecionou-se a horta comunitária do bairro Itararé (Dirceu Arcoverde II), uma das maiores da América Latina, medindo 27 ha, como objeto deste estudo (imagem 1). A proposta foi identificar o perfil dos horticultores, a possível presença da matemática em suas

\footnotetext{
${ }^{1}$ Licenciatura em Matemática, Instituto Federal do Piauí, nepomucenocarina0@gmail.com

${ }^{2}$ Licenciatura em Matemática, Instituto Federal do Piauí, wostinosn@ hotmail.com

${ }^{3}$ Me. Ciências e Engenharia de Materiais, IFPI, evangelista@ifpi.edu.br

${ }^{4}$ Dra. em Letras/Linguística, IFPI, fran2.barros@ifpi.edu.br
} 
atividades e sua complexidade para, assim, compararmos com as recomendações de Engenheiros Agrônomos e Técnicos Agrícolas, presentes no Manual do Horticultor, que consta métodos e valores para o cultivo orgânico de hortaliças (imagem 2).

A horta escolhida faz parte de um conjunto de ações realizadas pela prefeitura para o enfrentamento da pobreza, que beneficiam famílias de baixa renda. Essas pessoas aprendem e desenvolvem atividades de horticultura, desde a produção de canteiros até a comercialização do que se é produzido. Os beneficiados são auxiliados inicialmente por cartilhas (Manual do Horticultor) que a prefeitura disponibiliza.

Para a coleta de dados utilizou-se uma entrevista estruturada, contendo 15 perguntas, que foi aplicada junto a dez horticultores. Somou-se a este instrumento a técnica de observação direta, realizada por meio de visitas à horta, objeto deste estudo. Os entrevistados são horticultores experientes e atualmente ativos na horta comunitária do bairro Dirceu, em Teresina/PI. Mesmo muitos não tendo frequentado a escola até a conclusão do ensino fundamental (90\% não concluíram o ensino fundamental e 10\% chegaram até o ensino médio), e na maioria possuindo idades avançadas (20\% de 30 à 49 anos; $50 \%$ de 50 à 69 anos e 30\% de 70 à 80), eles afirmam que essas dificuldades não atrapalham a preparação do canteiro, o uso de inseticidas e nem a venda dos produtos da horta. Mesmo se tratando de hortas familiares que, muitas vezes, os conhecimentos são passados de pai para filho, eles dizem que com a ida das crianças para escola e com o aprendizado que lhes são passados, a produção tem aumentado e o desperdício tem diminuído bastante.

Ressalta-se que o mais instigante da pesquisa é que, na maioria dos casos, muitos sequer têm o conhecimento necessário para entender o que a cartilha contém, haja vista que muitos nem são alfabetizados. Apesar de todos saberem da existência da cartilha e conhecerem o objetivo de seguir as orientações nela contida - auxiliar os horticultores nos procedimentos de cultivo orgânico de hortaliças -todos os entrevistados só se utilizam dela nos primeiros meses de plantio.

Notou-se que, apesar de existirem cálculos exatos para desenvolver determinadas atividades do dia a dia, na prática, existe a exclusão de tais cálculos. Esses cálculos, que necessitam de conhecimento de alguns conteúdos de matemática, são vivenciados com naturalidade, de modo assistemático, a exemplo do que fazem os horticultores no preparo de canteiros e covas (tabela 1 ).

Ao fim do estudo, constatou-se que os horticultores utilizam métodos e estratégias bastante diversificados. Apesar disso, os resultados obtidos por eles são bastante semelhantes aos que são almejados pela cartilha disponibilizada pela prefeitura. 
Imagem1: Horta comunitária do bairro Itararé Fonte: Própria
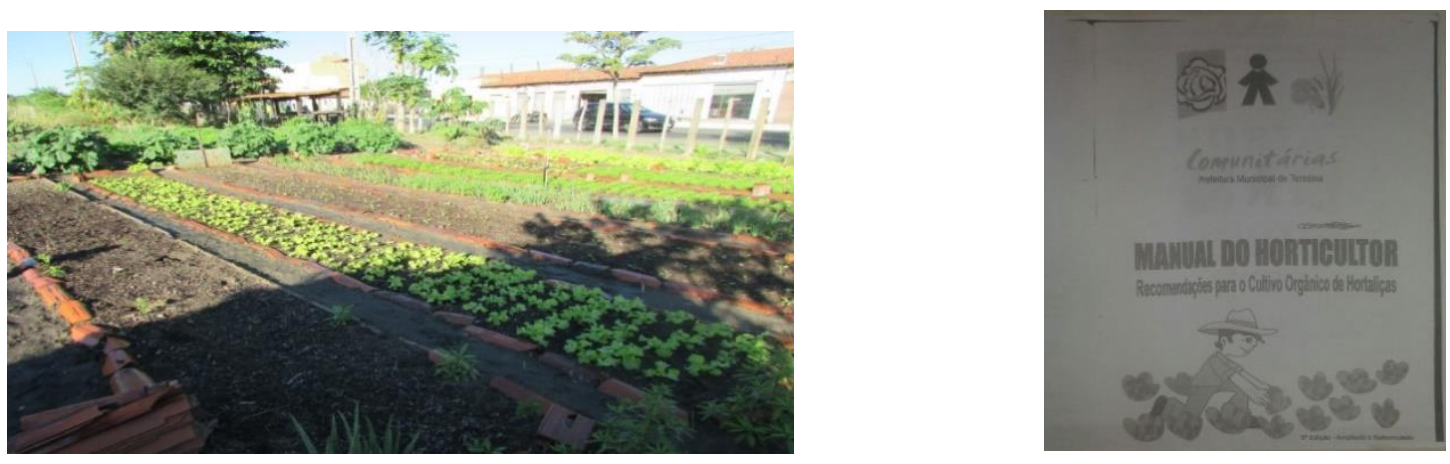

Imagem 2: Manual do Horticultor Fonte: Própria

Tabela 1-Comparação das medidas utilizadas pelos horticultores e as recomendadas pela cartilha.

\begin{tabular}{lll}
\hline & Manual do Horticultor & Prática do Horticultor \\
\hline Unidade de medida & Metros/ centímetros & Noção de experiências acumuladas \\
\hline $\begin{array}{l}\text { Ferramenta utilizada para } \\
\text { medir }\end{array}$ & Fita métrica & $\begin{array}{l}\text { Objetos distintos de tamanhos } \\
\text { variados (Ex.: Cabo de madeira, } \\
\text { cano de pvc, etc.) }\end{array}$
\end{tabular}

*Como as medidas feitas pelos horticultores não são concretas, traçamos um padrão unificado em metros/centímetros, para serem comparadas aos que a cartilha oferecem.

\begin{tabular}{lll}
\hline Largura do canteiro & De $1 \mathrm{~m}$ à $1,2 \mathrm{~m}$ & De $1 \mathrm{~m}$ à $1,2 \mathrm{~m}$ \\
\hline Comprimento do canteiro & $10 \mathrm{~m}$ & De $6,9 \mathrm{~m}$ à $10 \mathrm{~m}$ \\
\hline Ruas de circulação & $50 \mathrm{~cm}$ & $20 \mathrm{~cm}$ \\
\hline Diâmetro da cova & De $25 \mathrm{~cm}$ à $30 \mathrm{~cm}$ & De $15,7 \mathrm{~cm}$ à $20 \mathrm{~cm}$ \\
\hline Profundidade da cova & De $25 \mathrm{~cm}$ à $30 \mathrm{~cm}$ & De $10 \mathrm{~cm}$ à $19 \mathrm{~cm}$ \\
\hline
\end{tabular}

Fonte: Autoria própria (2018)

\section{CONSIDERAÇÕES}

Esses trabalhadores em suas atividades de horticultura utilizam conteúdos matemáticos, mesmo que de modo assistemático, a exemplo de proporção e medidas, que lhes são necessários para o desenvolvimento das atividades da horta, tais como: medir canteiros, calcular a quantidade necessária de adubo de acordo com o tamanho do canteiro, realizar a comercialização do produto produzido, etc.).

Consoante Saviani (2007), a própria necessidade de sobrevivência humana exige que haja entre trabalho e educação uma relação de identidade, ou seja, a teoria não deve ser ensinada desvinculada da prática. Portanto, para obter melhor rendimento no processo de ensinoaprendizagem, os conteúdos devem ser contextualizados com atividades das rotinas dos alunos, objetivando dirimir essa dicotomia teoria/prática.

Portanto, acredita-se que esses horticultores, provavelmente, teriam mais sucesso caso possuíssem alguma familiaridade com a teoria desses conteúdos que necessitam para 
desenvolverem suas atividades. Em vista disso, pretende-se desenvolver um projeto de extensão que contemplo um curso de Matemática relacionado ao cotidiano desses trabalhadores, a fim de se avaliar, com mais precisão, a eficácia da aliança teoria/prática no processo de aprendizagem.

\section{REFERÊNCIAS}

BRANCO, Calmon Castelo et al. Manual do Horticultor-Recomendações para o Cultivo Orgânico de Hortaliças. SDR - Superintendência de Desenvolvimento Rural (Prefeitura municipal de Teresina - PMT); $3^{\mathrm{a}}$ ed., Teresina: editora, 2013.

CUNHA, César Pessoa. A Importância da Matemática no cotidiano. Revista Científica Multidisciplinar Núcleo do Conhecimento. Edição 04. Ano 02, Vol. 01. Pp. 641-650, Julho de 2017. ISSN:2448-0959.

SAVIANI, D. Trabalho e educação: fundamentos ontológicos e históricos. Revista Brasileira de Educação. Rio de Janeiro, v. 12, n. 34, Pp. 152-165, jan./abr. 2007. 